Revista Brasileira de

Engenharia Agrícola e Ambiental

v.15, n.10, p.1021-1029, 2011

Campina Grande, PB, UAEA/UFCG - http://www.agriambi.com.br

agriambi

Protocolo 231.10 - 16/12/2010 • Aprovado em 09/08/2011

\title{
Atributos químicos de solo sob produção orgânica influenciados pelo preparo e por plantas de cobertura
}

\author{
Eurâimi de Q. Cunha ${ }^{1}$, Luís F. Stone ${ }^{2}$, Agostinho D. Didonet ${ }^{2}$, \\ Enderson P. de B. Ferreira ${ }^{2}$, José A. A. Moreira ${ }^{2} \&$ Wilson M. Leandro ${ }^{3}$
}

Este trabalho objetivou determinar a influência das plantas de cobertura crotalária (Crotalaria juncea), guandu (Cajanus cajan (L.) M illsp), mucuna-preta (M ucuna aterrima), sorgo vassoura (Sorgum technicum) e pousio, nos atributos químicos de solo cultivado com feijão e milho orgânicos, sob semeadura direta (SD) e preparo convencional (PC). O trabalho foi conduzido em Santo Antônio de Goiás, GO, em Latossolo Vermelho distrófico, no delineamento de blocos ao acaso, com quatro repetições. Em novembro de 2003 foram instalados quatro experimentos, dois em SD e dois em PC. Em cada preparo do solo um experimento foi conduzido com feijão e outro com milho. Amostragens de solo foram realizadas em setembro de 2003 e em novembro de 2007, nas camadas de 0-0,10 e 0,10-0,20 m. 0 pH e os teores de $\mathrm{P}, \mathrm{K}^{+}, \mathrm{Ca}^{2+}, \mathrm{M} \mathrm{g}^{2+}, \mathrm{Cu}^{2+}, \mathrm{Zn}^{2+}, \mathrm{Fe}^{3+}, \mathrm{Mn}^{2+}, \mathrm{H}^{+}+\mathrm{Al}^{3+}$ e $\mathrm{M}$.O foram analisadas e calculadas a capacidade de troca catiônica e a saturação por bases. Após quatro anos as plantas de cobertura não diferiram entre si quanto aos seus efeitos nos atributos químicos do solo; no entanto, elevaram o teor de M.O. em relação à condição inicial, seja sob SD ou sob PC. Em geral, a reciclagem dos nutrientes pelas plantas de cobertura não foi suficiente para a manutenção dos teores de $\mathrm{P}, \mathrm{K}^{+}, \mathrm{Fe}^{3+}$ e $\mathrm{Mn}^{2+}$ no solo.

Palavras-chave: Phaseolus vulgaris L., Zea mays, semeadura direta, preparo convencional, fertilidade do solo

\section{Chemical attributes of soil under organic production as affected by cover crops and soil tillage}

\begin{abstract}
This study aimed to determine the influence of the cover crops sunhemp (Crotalaria juncea), pigeon pea (Cajanus cajan (L.) M illsp), velvet bean (M ucuna aterrima), sorghum (Sorgum technicum), and fallow on chemical attributes of soil cultivated with organic common bean and corn, under no-tillage (NT) and conventional tillage (CT) systems. The work was conducted in Santo Antônio de Goiás-GO , in O xisol, in a randomized block design, with four replications. In November 2003 four experiments were installed, two of them under NT and the other two in CT. In each soil management system, an experiment was carried out with common bean crop and another with corn. Samples were taken from soil layers of $0-0.10$ and $0.10-0.20 \mathrm{~m}$ in September 2003 and in November 2007. The soil pH and the contents of $P$, $\mathrm{K}^{+}, \mathrm{Ca}^{2+}, \mathrm{Mg}^{2+}, \mathrm{Cu}^{2+}, \mathrm{Zn}^{2+}, \mathrm{Fe}^{3+}, \mathrm{Mn}^{2+}, \mathrm{H}^{+}+\mathrm{Al}^{3+}$, and soil organic matter were analyzed, and cation exchange capacity and base saturation 'were calculated. After four years, cover crops did not differ in their effects on soil chemical attributes, how ever, they increased the content of organic matter in relation to initial condition, under N T or in CT. In general, the nutrient recycling by cover crops was not sufficient to maintain the $\mathrm{P}, \mathrm{K}^{+}, \mathrm{Fe}^{3+}$ and $\mathrm{Mn}^{2+}$ contents in the soil.
\end{abstract}

Key words: Phaseolus vulgaris L., Zea mays L., no-tillage, conventional tillage, soil fertility

Doutorando do Curso de Pós-Graduação em Agronomia da UFG, Goiânia, GO. Fone (62) 3534-9801. E-mail: euraimi@yahoo.com.br 2 Embrapa Arroz e Feijão, CP 179, CEP 75375-000, Santo Antônio de Goiás, GO. Fone (62) 3533-2151. E-mail: stone@cnpaf.embrapa.br; didonet@cnpaf.embrapa.br; enderson@cnpaf.embrap.br; jaloisio@cnpms.embrapa.br

3 Escola de Agronomia e Engenharia de Alimentos/U FG, CP 131, CEP 74001-970, Goiânia, Go. Fone (62) 3521-1530. E-mail: wilson.mozena@pq.cnpq.br 


\section{INTRODUÇÃO}

O aumento da procura pelos consumidores por produtos orgânicos e o crescente interesse dos agricultores por sistemas alternativos de produção que aumentem a rentabilidade, melhorem a qualidade de vida do meio rural e preservem a capacidade produtiva do solo a longo prazo, têm impulsionado a busca de informações sobre a contribuição dos sistemas de preparo do solo e de plantas de cobertura na manutenção da fertilidade do solo sob cultivo orgânico.

O efeito da cobertura vegetal sobre atributos químicos do solo está relacionado com a espécie de planta usada, a classe do solo, as condições climáticas e, sobremaneira, com o tipo de manejo dispensado à planta de cobertura (Andreola et al., 2000; Osterroht, 2002). Quando a cobertura é utilizada na superfície do solo, sem incorporação, como na semeadura direta, os nutrientes menos móveis, como o fósforo e o carbono orgânico, se concentram nos $0,10 \mathrm{~m}$ superficiais do solo. Por outro lado, quando a cobertura do solo é incorporada pelo sistema convencional de preparo do solo ocorre distribuição da matéria orgânica na camada arável e não se verifica acúmulo significativo de carbono orgânico do solo (De Maria \& Castro, 1993). De Maria et al. (1999) verificaram, em Latossolo, que a semeadura direta apresentou maior acúmulo de fósforo, potássio, cálcio e magnésio e aumentou o $\mathrm{pH}$, a saturação por bases e a capacidade de troca de cátions em relação ao preparo convencional do solo, efeito este mais evidente na camada de 0,00-0,05 m, sobretudo do fósforo, em virtude da reciclagem do fósforo orgânico e da redução da fixação. Teixeira et al. (2003) notaram, em Argissolo Vermelho-Amarelo, maior valor de $\mathrm{pHe}$ teores de carbono orgânico, cobre, manganês e zinco nessa camada do solo sob semeadura direta em relação a preparos com revolvimento do solo. Moreti et al. (2007), por sua vez, constataram que a distribuição dos elementos minerais na camada de 0,00-0,20 m de um Latossolo Vermelho foi semelhante entre a semeadura direta e o preparo convencional.

Segundo Osterroht (2002), entre os efeitos do uso de plantas de cobertura sobre a fertilidade do solo estão a adição de carbono orgânico, a maior capacidade de troca de cátions e a menor acidez; o aumento do fósforo disponível pela ação combinada de micorrizas e exsudatos das raízes; a complexação orgânica do alumínio e manganês que se encontram em níveis tóxicos no solo; a adição de nitrogênio ao sistema pela fixação biológica; a disponibilização de micronutrientes, fixados e indisponíveis devido ao uso excessivo de calagem e adubos químicos e a melhoria no desenvolvimento dos cultivos, aumentando a estabilidade nas produções, ao longo dos anos.

Entre as espécies empregadas como planta de cobertura, as leguminosas se destacam por formarem associações simbióticas com bactérias fixadoras de nitrogênio atmosférico, resultando no aporte de quantidades expressivas desse nutriente no solo, contribuindo com a nutrição de culturas subsequentes. Outra característica importante das leguminosas é sua baixa relação $\mathrm{C} / \mathrm{N}$, quando comparada com plantas de outras famílias. Este aspecto, aliado à presença de compostos solúveis, favorece sua decomposição e mineralização por micro-organismos do solo e a reciclagem de nutrientes (Perin et al., 2004).
Alcântara et al. (2000) observaram que o guandu (Cajanus cajan (L.) Millsp) se destacou quanto às melhorias na fertilidade do solo na avaliação realizada aos 90 dias após o manejo e a crotalária (Crotalaria juncea L.), de mineralização mais lenta, na avaliação realizada aos 120 dias. Na avaliação realizada aos 150 dias não foram encontrados benefícios das plantas de cobertura nas propriedades químicas do solo. Moreti et al. (2007) verificaram que a crotalária e o milheto (Pennisetum americanum L.) não alteraram os atributos químicos do solo, tanto na semeadura direta quanto incorporados ao solo pelo preparo convencional. Almeida et al. (2008), após três anos de implantação da semeadura direta e com preparo convencional do solo, não verificaram efeito significativo das plantas de cobertura guandu, crotalária, mucuna-preta (Mucuna aterrima, sinonímia Stizolobium aterrimum Piper \& Tracy), milheto e do pousio sobre o $\mathrm{pH}$, acidez potencial e teor de matéria orgânica no solo. Correia \& Durigan (2008), por outro lado e após dois anos de semeadura direta comparando diversas espécies de gramíneas usadas como cobertura do solo e a vegetação espontânea, observaram que esta última proporcionou maiores valores de $\mathrm{pH}$, cálcio e magnésio trocáveis, saturação por bases e capacidade de troca de cátions efetiva, e as plantas de cobertura, maior concentração de fósforo e matéria orgânica no solo.

Os efeitos proporcionados pelos compostos orgânicos dos resíduos vegetais de plantas de cobertura sobre a química do solo, são transientes. No entanto, podem mitigar os efeitos acidificantes causados por grupos carboxílicos e fenólicos gerados durante a decomposição de resíduos vegetais pela reação dos adubos nitrogenados amídicos e amoniacais (processo de nitrificação) e pela exportação de bases pelas colheitas (Anghinoni \& Nicolodi, 2004).

É fundamental a utilização de espécies produtoras de palhada que mobilizem os nutrientes na camada agricultável, retendo-os na sua fitomassa e os devolvendo ao solo durante a decomposição (Denardin \& Kochhann, 1993), mesmo havendo necessidade de se avaliar a real contribuição dessas espécies e do seu manejo, com a finalidade de manter ou elevar a fertilidade do solo em áreas sob produção orgânica e melhorar a produtividade das culturas comerciais. Assim, o presente trabalho teve como objetivo determinar a influência de plantas de cobertura nos atributos químicos do solo cultivado com feijão e milho orgânicos, sob semeadura direta e preparo convencional do solo, na região do Cerrado.

\section{Material e MÉTOdos}

Este trabalho foi conduzido na Fazenda Capivara, da Embrapa Arroz e Feijão, localizada no município de Santo Antônio de Goiás, GO, compreendida entre as coordenadas $16^{\circ} 31^{\prime} 18^{\prime \prime} \mathrm{S}$, $49^{\circ} 18^{\prime} 45^{\prime \prime} \mathrm{W}, 16^{\circ} 31^{\prime} 18^{\prime \prime} \mathrm{S}, 49^{\circ} 16^{\prime} 07^{\prime \prime} \mathrm{W}, 16^{\circ} 29^{\prime} 02^{\prime \prime} \mathrm{S}, 49^{\circ} 16^{\prime}$ $07^{\prime \prime} \mathrm{W}, 16^{\circ} 29^{\prime} 02^{\prime \prime} \mathrm{S}$ e $49^{\circ} 18^{\prime} 45^{\prime \prime} \mathrm{W}$, e com altitude média de 823 m. O clima, conforme classificação de Köppen, é Aw, tropical de savana, megatérmico. O regime pluvial é bem definido, com período chuvoso de outubro a abril e seco de maio a setembro (Tabela 1), com precipitação média anual variando de 1024,0 a $1891,9 \mathrm{~mm}$ no período considerado (Silva et al., 2010). O solo 
Tabela 1. Totais mensais de precipitação pluvial, no período de 2004 a 2007, em Santo Antônio de G oiás, Go

\begin{tabular}{|c|c|c|c|c|c|c|c|c|c|c|c|c|c|}
\hline \multirow{2}{*}{ Ano } & \multicolumn{13}{|c|}{ Precipitação pluvial (mm) } \\
\hline & Jan & Fev & Mar & $A b r$ & Mai & Jun & Jul & Ago & Set & Out & Nov & Dez & Total \\
\hline 2004 & 456,6 & 264,3 & 440,2 & 102,8 & 30,8 & 0,0 & 4,9 & 0,0 & 2,5 & 154,7 & 157,9 & 277,2 & 1891,9 \\
\hline 2005 & 213,7 & 72,9 & 332,9 & 56,7 & 61,2 & 11,5 & 0,0 & 0,8 & 49,1 & 95,7 & 219,4 & 497,2 & 1611,1 \\
\hline 2006 & 167,7 & 234,3 & 245,8 & 231,0 & 54,9 & 0,0 & 0,0 & 5,9 & 68,2 & 219,5 & 202,7 & 295,1 & 1725,1 \\
\hline 2007 & 210,9 & 196,3 & 49,3 & 92,6 & 6,1 & 0,0 & 9,3 & 0,0 & 23,7 & 57,0 & 171,5 & 207,3 & 1024,0 \\
\hline
\end{tabular}

do local é um Latossolo Vermelho distrófico, de textura francoargilosa, com $410 \mathrm{~g} \mathrm{~kg}^{-1}$ de areia, $270 \mathrm{~g} \mathrm{~kg}^{-1}$ de silte e $320 \mathrm{~g} \mathrm{~kg}^{-1}$ de argila, na camada de 0,00-0,20 m. Antes da implantação dos experimentos foram não apenas aplicados em toda a área mas também incorporados com grade aradora, $1.620 \mathrm{~kg} \mathrm{ha}^{-1} \mathrm{de}$ fosfato natural Arad $\left(33 \%\right.$ de $\left.\mathrm{P}_{2} \mathrm{O}_{5}\right)$ e $2.000 \mathrm{~kg} \mathrm{ha}^{-1}$ de calcário. A vegetação original da área experimental era do tipo cerradão e vinha sendo cultivada no sistema convencional de preparo do solo (gradagens aradora e niveladora) com rotação milho e soja.

Em novembro de 2003 foram instalados quatro experimentos, os quais estão sendo conduzidos segundo os preceitos da produção orgânica. Dois experimentos foram conduzidos em semeadura direta e nos outros dois foi realizado o preparo convencional do solo com grades aradora e niveladora, operando até $0,10-0,15 \mathrm{~m}$ de profundidade. Em cada sistema de preparo do solo foi conduzido um experimento com a cultura do milho e outro com a do feijão das águas. Em todos os experimentos foram comparadas, no delineamento de blocos ao acaso, com quatro repetições, as plantas de cobertura: crotalária (Crotalaria juncea), guandu (Cajanus cajan (L.) Millsp), mucuna-preta (Mucuna aterrima), sorgo vassoura (Sorgum technicum) e pousio (vegetação espontânea). A vegetação espontânea era constituída basicamente de picãopreto (Bidens pilosa), capim pé-de-galinha (Eleusine indica) e leiteiro (Euphorbia heterophylla), com menores ocorrências de braquiária (Brachiaria decumbens), corda de viola (Ipomoea grandifolia), caruru (Amaranthus deflexus), erva de santa Luzia (Chamaisice viridis L.), trapoeraba (Commelina benghalensis), mentrasto (Ageratum conyzoides), beldroega (Portulaca oleracea), guanxuma (Sida cordifolia) e Maria pretinha (Solanum americanum Mill).

As plantas de cobertura foram semeadas em abril de cada ano e conduzidas no sistema de semeadura direta. Por ocasião da semeadura do milho e feijão, em novembro, foram manejadas com rolo-faca e deixadas sobre o solo (semeadura direta) ou incorporadas (preparo convencional). Elas foram semeadas sem adubação no espaçamento de $0,45 \mathrm{~m}$ entre linhas, utilizandose 60 sementes por metro de crotalária, guandu e sorgo e 20 sementes por metro de mucuna. O feijoeiro (Phaseolus vulgaris L.) cv. Pérola foi semeado no mesmo espaçamento, com 16 sementes por metro e o milho (Zea mays L.) cv. AG 1051 no espaçamento de $0,90 \mathrm{~m}$, com cinco sementes por metro, também sem adubação. A área das parcelas com feijão era de $27,00 \mathrm{~m}^{2}$ $(2,70 \times 10,00 \mathrm{~m})$ e as com milho de $54 \mathrm{~m}^{2}(5,40 \times 10,00 \mathrm{~m})$.

Foram realizadas, por parcela, duas amostragens de solo nas camadas de 0,00-0,10 e 0,10-0,20 m para análise química, a primeira em setembro de 2003 (controle), após o revolvimento do solo para incorporar os restos culturais, no caso do preparo convencional, mas antes da semeadura do feijoeiro e do milho, caracterizando a área em estudo e a segunda em novembro de 2007.

Foram analisados o $\mathrm{pH}$ do solo e os teores de $\mathrm{P}, \mathrm{K}^{+}, \mathrm{Ca}^{2+}$, $\mathrm{Mg}^{2+}, \mathrm{Cu}^{2+}, \mathrm{Zn}^{2+}, \mathrm{Fe}^{3+}, \mathrm{Mn}^{2+}, \mathrm{H}^{+}+\mathrm{Al}^{3+}$ e matéria orgânica, e calculadas a capacidade de troca de cátions a pH 7 (CTC) e a saturação por bases $(\mathrm{V})$. $\mathrm{O}$ pH foi determinado em água. $\mathrm{O}$ fósforo e o potássio foram extraídos com a solução de Mehlich $1\left(\mathrm{HCl}\right.$ a $0,5 \mathrm{~N}+\mathrm{H}_{2} \mathrm{SO}_{4}$ a $\left.0,025 \mathrm{~N}\right)$ e determinados, respectivamente, em colorímetro e fotômetro de chama. $\mathrm{O} \mathrm{Ca}^{2+}$ e o $\mathrm{Mg}^{2+}$ foram extraídos em $\mathrm{KCl}$ a $1 \mathrm{~N}$ e determinados por titulação de EDTA. Os micronutrientes foram determinados em espectrofotômetro de absorção atômica utilizando-se o extrator Mehlich $1 . \mathrm{O} \mathrm{H}^{+}+\mathrm{Al}^{3+}$ foi determinado por titulometria, usandose solução de acetato de cálcio $1 \mathrm{~N}$ a pH 7 para sua extração. A matéria orgânica foi determinada pelo método de Walkley \& Black (1934). As análises laboratoriais foram realizadas de acordo com EMBRAPA (1997).

Os dados relativos ao ano de 2007 foram submetidos à análise de variância por camada, utilizando-se o procedimento GLM do programa estatístico SAS (SAS Institute, 1999), sendo as médias comparadas pelo teste de Tukey a $5 \%$ de probabilidade. As médias dos tratamentos foram comparadas com as da análise inicial do solo, feita em 2003 (controle) pelo teste de Dunnett a $5 \%$ de probabilidade. Foram estimadas correlações de Pearson entre o teor de matéria orgânica e os teores dos micronutrientes considerando-se, conjuntamente, as duas camadas amostradas e os quatro experimentos.

\section{RESULTADOS E DISCUSSÃO}

Os rendimentos de matéria seca das plantas de cobertura foram semelhantes nos dois sistemas de preparo do solo (Tabela 2), com maiores valores para o sorgo. Como elas foram semeadas no final da estação chuvosa (Tabela 1), seus rendimentos foram baixos em comparação com os normalmente obtidos com semeadura no início da estação (Menezes \& Leandro, 2004; Menezes et al., 2009), com exceção do sorgo, mais adaptado à pouca disponibilidade hídrica. O rendimento de grãos do feijoeiro e do milho não foi afetado pelas plantas de cobertura nos dois sistemas de preparo do solo. Alves \& Suzuki (2004) e Almeida et al. (2008), também em Latossolo Vermelho, não observaram diferenças no rendimento dessas culturas cultivadas após guandu, crotalária e mucuna, tanto na semeadura direta como no preparo convencional.

Após quatro anos de cultivo não se observaram diferenças entre as plantas de cobertura quanto aos seus efeitos nos atributos químicos do solo avaliados nas camadas de 0,00-0,10 $\mathrm{m}$ e $0,10-0,20 \mathrm{~m}$, seja sob preparo convencional (Tabelas 3 e 5) ou semeadura direta (Tabelas 4 e 6). 
Tabela 2. M édias do rendimento de biomassa seca da parte aérea das plantas de cobertura e de grãos de feijão e milho, de acordo com o sistema de preparo do solo, no período de 2004 a 2007

\begin{tabular}{|c|c|c|c|c|c|c|}
\hline \multirow{3}{*}{ Tratamento } & \multicolumn{6}{|c|}{ Rendimento $^{*}\left(\mathrm{~kg} \mathrm{ha}^{-1}\right)$} \\
\hline & \multicolumn{3}{|c|}{ Preparo convencional } & \multicolumn{3}{|c|}{ Semeadura direta } \\
\hline & Cobertura & Feijão & Milho & Cobertura & Feijão & Milho \\
\hline Pousio & $1.460 \mathrm{~b}$ & $808 a$ & $5.503 a$ & $1.525 \mathrm{~b}$ & $585 a$ & $4.476 a$ \\
\hline Crotalária & $3.532 b$ & $772 \mathrm{a}$ & $6.553 a$ & $3.722 b$ & $910 \mathrm{a}$ & $5.795 a$ \\
\hline Guandu & $4.023 b$ & $767 a$ & $6.591 \mathrm{a}$ & $3.761 b$ & 929 a & $5.270 \mathrm{a}$ \\
\hline Mucuna & $3.933 b$ & $869 a$ & 6.793 a & $4.046 b$ & 838 a & $6.564 a$ \\
\hline Sorgo & $11.120 \mathrm{a}$ & $741 \mathrm{a}$ & $4.315 a$ & $9.943 a$ & $722 \mathrm{a}$ & $4.070 \mathrm{a}$ \\
\hline C.V. (\%) & 29,9 & 35,8 & 33,8 & 30,7 & 29,2 & 25,1 \\
\hline
\end{tabular}

* Médias nas colunas seguidas da mesma letra não diferem significativamente pelo teste de Tukey a $5 \%$ de probabilidade

Tabela 3. Valores médios de $\mathrm{MO}, \mathrm{pH}, \mathrm{Ca}^{2+}, \mathrm{M} \mathrm{g} \mathrm{g}^{2+}, \mathrm{P}, \mathrm{K}^{+}, \mathrm{Cu}^{2+}, \mathrm{Zn}^{2+}, \mathrm{Fe}^{3+}, \mathrm{Mn}^{2+}, \mathrm{CTC}$ e $\mathrm{V}$, de acordo com as plantas de cobertura e camadas estudadas, no experimento sob preparo convencional com a cultura do feijão, em Santo Antônio de Goiás, G O, 2007*

\begin{tabular}{|c|c|c|c|c|c|c|c|c|}
\hline \multirow{2}{*}{ Tratamento } & \multicolumn{8}{|c|}{ Profundidade (m) } \\
\hline & $0-0,10$ & $0,10-0,20$ & $0-0,10$ & $0,10-0,20$ & $0-0,10$ & $0,10-0,20$ & $0-0,10$ & $0,10-0,20$ \\
\hline & \multicolumn{2}{|c|}{ MO } & \multicolumn{2}{|c|}{$\mathrm{pH}$} & & & \multicolumn{2}{|c|}{$\mathrm{Mg}^{2+}$} \\
\hline & \multicolumn{2}{|c|}{$\mathrm{g} \mathrm{dm}^{-3}$} & \multicolumn{2}{|c|}{ água $(1: 2,5)$} & \multicolumn{4}{|c|}{$\mathrm{cmol}_{\mathrm{c}} \mathrm{dm}^{-3}$} \\
\hline Pousio & $21,2 a^{*}$ & $20,0 a^{*}$ & $6,1 \mathrm{a}$ & $6,1 \mathrm{a}$ & $3,6 a$ & $3,5 a$ & 1,2 a & $1,2 \mathrm{a}$ \\
\hline Crotalária & $21,5 a^{*}$ & 20,2 a* & $6,2 a$ & $6,1 \mathrm{a}$ & $3,5 \mathrm{a}$ & $3,4 a$ & $1,2 \mathrm{a}$ & $1,2 \mathrm{a}$ \\
\hline Guandu & $21,5 a^{*}$ & 20,5 a* & $6,2 a$ & $6,1 \mathrm{a}$ & $3,4 a$ & $3,3 a$ & $1,1 \mathrm{a}$ & $1,1 \mathrm{a}$ \\
\hline Mucuna & $21,2 a^{*}$ & 20,0 a* & $6,2 a$ & $6,2 \mathrm{a}$ & $3,6 \mathrm{a}$ & $3,6 \mathrm{a}$ & $1,2 \mathrm{a}$ & $1,1 \mathrm{a}$ \\
\hline Sorgo & 21,8 a* & 20,2 a* & $6,2 a$ & $6,2 \mathrm{a}$ & $3,5 \mathrm{a}$ & $3,5 \mathrm{a}$ & $1,2 \mathrm{a}$ & $1,1 \mathrm{a}$ \\
\hline C.V. (\%) & 2,6 & 2,8 & 1,8 & 1,7 & 6,0 & 7,7 & 5,8 & 7,1 \\
\hline \multirow[t]{3}{*}{ Controle } & 20,0 & 18,0 & 6,2 & 6,2 & 3,7 & 3,7 & 1,2 & 1,2 \\
\hline & \multicolumn{2}{|c|}{$P$} & \multicolumn{2}{|c|}{$\mathrm{K}^{+}$} & \multicolumn{2}{|c|}{$\mathrm{Cu}^{2+}$} & \multicolumn{2}{|c|}{$\mathrm{Zn}^{2+}$} \\
\hline & \multicolumn{8}{|c|}{$\mathrm{mg} \mathrm{dm}^{-3}$} \\
\hline Pousio & $8,9 a^{*}$ & $7,2 a^{*}$ & 97 a & $82 a$ & $2,4 a$ & $2,3 a$ & $2,8 \mathrm{a}$ & $2,4 a^{*}$ \\
\hline Crotalária & $7,1 a^{*}$ & $9,1 \mathrm{a}$ & $112 \mathrm{a}$ & $111 \mathrm{a}$ & $2,2 \mathrm{a}$ & $2,2 a$ & $2,7 \mathrm{a}$ & $2,8 \mathrm{a}$ \\
\hline Guandu & $5,7 a^{*}$ & $7,1 a^{*}$ & $106 a$ & $104 a$ & $2,2 \mathrm{a}$ & $2,2 a$ & $2,6 a^{*}$ & $2,4 a^{*}$ \\
\hline Mucuna & $10,0 a^{*}$ & $10,0 \mathrm{a}$ & $98 a$ & $87 a$ & $2,1 \mathrm{a}$ & $2,1 \mathrm{a}$ & $2,5 a^{*}$ & $2,4 a^{*}$ \\
\hline Sorgo & $7,0 a^{*}$ & $4,6 a^{*}$ & $85 a$ & $74 a$ & $2,4 a$ & $2,4 a$ & $2,4 a^{*}$ & $2,1 a^{*}$ \\
\hline C.V. (\%) & 36,8 & 53,6 & 32,4 & 31,5 & 8,6 & 8,5 & 8,3 & 16,1 \\
\hline \multirow[t]{3}{*}{ Controle } & 25,2 & 15,5 & 147,0 & 104,0 & 2,3 & 2,3 & 3,1 & 3,4 \\
\hline & \multicolumn{2}{|c|}{$\mathrm{Fe}^{3+}$} & \multicolumn{2}{|c|}{$\mathrm{Mn}^{2+}$} & \multicolumn{2}{|c|}{ CTC } & \multicolumn{2}{|c|}{$\mathrm{V}$} \\
\hline & \multicolumn{4}{|c|}{$\mathrm{mg} \mathrm{dm}^{-3}$} & \multicolumn{2}{|c|}{$\mathrm{cmol}_{\mathrm{c}} \mathrm{dm}^{-3}$} & \multicolumn{2}{|c|}{$\%$} \\
\hline Pousio & $22 a^{*}$ & $21 a^{*}$ & $47 a^{*}$ & $43 a^{*}$ & $9,5 a$ & $9,2 a$ & 53,3 a & $53,3 a$ \\
\hline Crotalária & $23 a^{*}$ & $22 a^{*}$ & $48 a^{*}$ & $45 a^{*}$ & $9,2 \mathrm{a}$ & $9,1 \mathrm{a}$ & $54,1 \mathrm{a}$ & $54,1 \mathrm{a}$ \\
\hline Guandu & 21 a* & 21 a* & $48 a^{*}$ & $45 a^{*}$ & 8,6 a & $8,8 a$ & 54,9 a & $53,3 a$ \\
\hline Mucuna & $24 a^{*}$ & $23 a^{*}$ & $50 a^{*}$ & $48 a^{*}$ & $9,1 \mathrm{a}$ & $8,9 a$ & $55,7 \mathrm{a}$ & $56,6 a$ \\
\hline Sorgo & $26 a^{*}$ & $24 a^{*}$ & $47 a^{*}$ & $45 a^{*}$ & $9,2 \mathrm{a}$ & $8,8 a$ & $54,1 \mathrm{a}$ & $55,7 a$ \\
\hline C.V. (\%) & 11,1 & 12,5 & 9,4 & 10,1 & 6,2 & 7,0 & 6,7 & 6,2 \\
\hline Controle & 38,0 & 39,0 & 73,0 & 72,0 & 9,6 & 9,4 & 54,4 & 55,0 \\
\hline
\end{tabular}

* Médias nas colunas seguidas da mes ma letra não diferem significativamente pelo teste de Tukey a $5 \%$ de probabilidade e as seguidas de * diferem significativamente do controle pelo teste de Dunnett a $5 \%$ de probabilidade. $\mathrm{pH}$ : potencial hidrogeniônico, $\mathrm{Ca}^{2+}$ : cálcio, $\mathrm{Mg}^{2+}$ : magnésio, $\mathrm{P}:$ fósforo, $\mathrm{K}^{+}:$potássio, $\mathrm{Cu}^{2+}:$ cobre, $\mathrm{Zn}^{2+}:$ zinco, $\mathrm{Fe}^{3+}$ : ferro, $\mathrm{Mn}^{2+}:$ manganês, $\mathrm{M} 0$ : matéria orgânica, $\mathrm{CTC}$ : capacidade de troca catiônica, V: saturação por bases

Wutke et al. (2000) também não observaram, em Latossolo Vermelho sob preparo convencional após três anos da rotação do feijoeiro irrigado com milho e plantas de cobertura, diferenças entre pousio, milho, crotalária, mucuna, guandu e aveia preta (Avena strigosa Schreb) quanto ao $\mathrm{pH}$ e aos teores de matéria orgânica, fósforo, potássio, cálcio e magnésio. Corroborando com tal informação, Moreti et al. (2007), também em Latossolo Vermelho, verificaram, após um ano, que a crotalária e o milheto não alteraram os atributos químicos do solo, tanto na semeadura direta quanto incorporadas ao solo pelo preparo convencional.

Com base no trabalho de Fageria (2001), a quantidade de nutrientes exportados pelos grãos de feijão para a produção de $1 \mathrm{t}$ de grãos é igual a 3,$5 ; 2,7 ; 3,8$ e $22,2 \mathrm{~kg} \mathrm{ha}^{-1}$, respectivamente para o $\mathrm{Ca}, \mathrm{Mg}, \mathrm{Pe} \mathrm{Ke} \mathrm{14,0;} \mathrm{46,2;} \mathrm{90,0} \mathrm{e} \mathrm{16,6}$ $\mathrm{g} \mathrm{ha}^{-1}$, respectivamente para o Cu, $\mathrm{Zn}, \mathrm{Fe}$ e Mn. Para o milho, esses valores são 1,$1 ; 1,1 ; 2,2$ e $4,4 \mathrm{~kg} \mathrm{ha}^{-1}$, respectivamente para o $\mathrm{Ca}, \mathrm{Mg}$, P e K, e 1,8; 24,8; 26,6 e 10,6 $\mathrm{g} \mathrm{ha}^{-1}$, respectivamente para o $\mathrm{Cu}, \mathrm{Zn}, \mathrm{Fe}$ e $\mathrm{Mn}$.

Considerando esses valores e a produção de grãos do feijoeiro (Tabela 2), constata-se que a quantidade exportada pelos grãos de feijão após quatro anos de experimento variou de 8 a 13,6 a 10,9 a 14 e 52 a $82 \mathrm{~kg} \mathrm{ha}^{-1}$, respectivamente para o $\mathrm{Ca}, \mathrm{Mg}, \mathrm{P} \mathrm{e} \mathrm{K}$, e de 33 a 52, 108 a 172, 210 a 334 e 39 a $62 \mathrm{~g} \mathrm{ha}^{-1}$, respectivamente para o $\mathrm{Cu}, \mathrm{Zn}, \mathrm{Fe}$ e Mn. Para o milho, a 
Tabela 4. Valores médios de $\mathrm{MO}, \mathrm{pH}, \mathrm{Ca}^{2+}, \mathrm{M} \mathrm{g}^{2+}, \mathrm{P}, \mathrm{K}^{+}, \mathrm{Cu}^{2+}, \mathrm{Zn}^{2+}, \mathrm{Fe}^{3+}, \mathrm{Mn}^{2+}, \mathrm{CTC}$ e $\mathrm{V}$, de acordo com as plantas de cobertura e camadas estudadas, no experimento sob semeadura direta com a cultura do feijão, em Santo Antônio de Goiás, GO, 2007*

\begin{tabular}{|c|c|c|c|c|c|c|c|c|}
\hline \multirow{2}{*}{ Tratamento } & \multicolumn{8}{|c|}{ Profundidade (m) } \\
\hline & $0-0,10$ & $0,10-0,20$ & $0-0,10$ & $0,10-0,20$ & $0-0,10$ & $0,10-0,20$ & $0-0,10$ & $0,10-0,20$ \\
\hline & \multicolumn{2}{|c|}{ MO } & \multicolumn{2}{|c|}{$\mathrm{pH}$} & \multicolumn{2}{|c|}{$\mathrm{Ca}^{2+}$} & \multicolumn{2}{|c|}{$\mathrm{Mg}^{2+}$} \\
\hline & \multicolumn{2}{|c|}{$g \mathrm{dm}^{-3}$} & \multicolumn{2}{|c|}{ áqua $(1: 2,5)$} & \multicolumn{4}{|c|}{$\mathrm{cmol}_{\mathrm{c}} \mathrm{dm}^{-3}$} \\
\hline Pousio & $21,5 a^{*}$ & $20,2 a^{*}$ & $6,1 \mathrm{a}$ & $6,0 \mathrm{a}$ & $3,6 a$ & $3,5 \mathrm{a}$ & $1,3 \mathrm{a}$ & $1,3 \mathrm{a}$ \\
\hline Crotalária & $21,5 a^{*}$ & $20,0 a^{*}$ & $6,1 \mathrm{a}$ & $6,0 \mathrm{a}$ & $3,4 \mathrm{a}$ & $3,3 a$ & $1,2 \mathrm{a}$ & $1,2 \mathrm{a}$ \\
\hline Guandu & $21,2 a^{*}$ & $20,0 a^{*}$ & $6,1 \mathrm{a}$ & $6,1 \mathrm{a}$ & $3,6 \mathrm{a}$ & $3,6 a$ & $1,2 \mathrm{a}$ & $1,2 \mathrm{a}$ \\
\hline Mucuna & $21,8 a^{*}$ & $20,5 a^{*}$ & $6,1 \mathrm{a}$ & $6,2 a$ & $3,4 a$ & $3,3 a$ & $1,2 a$ & $1,1 \mathrm{a}$ \\
\hline Sorgo & $22,0 a^{*}$ & $20,8 a^{*}$ & $6,2 a$ & $6,1 \mathrm{a}$ & $3,5 a$ & $3,5 a$ & $1,2 \mathrm{a}$ & $1,2 \mathrm{a}$ \\
\hline C.V. (\%) & 2,2 & 2,2 & 1,8 & 1,6 & 10,3 & 10,8 & 13,6 & 12,5 \\
\hline \multirow[t]{3}{*}{ Controle } & 20,0 & 18,0 & 6,3 & 6,2 & 3,8 & 3,4 & 1,3 & 1,1 \\
\hline & \multicolumn{2}{|c|}{$P$} & \multicolumn{2}{|c|}{$\mathrm{K}^{+}$} & \multicolumn{2}{|c|}{$\mathrm{Cu}^{2+}$} & \multicolumn{2}{|c|}{$\mathrm{Zn}^{2+}$} \\
\hline & \multicolumn{8}{|c|}{$\mathrm{mg} \mathrm{dm}^{-3}$} \\
\hline Pousio & $18,1 \mathrm{a}$ & $19,8 \mathrm{a}$ & 90 a* & $99 a$ & $1,8 \mathrm{a}$ & $1,8 \mathrm{a}$ & $3,4 \mathrm{a}$ & $3,3 a$ \\
\hline Crotalária & $31,6 a$ & $15,1 \mathrm{a}$ & $95 a^{*}$ & $95 a$ & $2,2 \mathrm{a}$ & $2,0 a$ & $3,8 \mathrm{a}$ & $2,9 a$ \\
\hline Guandu & $20,6 a$ & $13,4 \mathrm{a}$ & 91 a* & $85 a$ & $1,7 \mathrm{a}$ & $1,8 \mathrm{a}$ & $3,7 \mathrm{a}$ & $2,8 \mathrm{a}$ \\
\hline Mucuna & $11,4 a^{*}$ & $13,0 \mathrm{a}$ & $96 a^{*}$ & $106 a$ & $1,6 \mathrm{a}$ & $1,8 \mathrm{a}$ & $2,9 a$ & $2,4 a$ \\
\hline Sorgo & $20,6 a$ & $19,4 \mathrm{a}$ & $85 a^{*}$ & $82 a$ & $1,9 a$ & $1,9 a$ & $3,6 \mathrm{a}$ & $2,9 a$ \\
\hline C.V. (\%) & 66,5 & 61,3 & 17,7 & 20,4 & 23,7 & 17,8 & 24,7 & 20,6 \\
\hline \multirow[t]{3}{*}{ Controle } & 36,9 & 25,9 & 144,0 & 112,0 & 2,1 & 2,0 & 4,0 & 3,2 \\
\hline & \multicolumn{2}{|c|}{$\mathrm{Fe}^{3+}$} & \multicolumn{2}{|c|}{$\mathrm{Mn}^{2+}$} & \multicolumn{2}{|c|}{ CTC } & \multicolumn{2}{|c|}{ V } \\
\hline & \multicolumn{4}{|c|}{$\mathrm{mg} \mathrm{dm}^{-3}$} & \multicolumn{2}{|c|}{$\mathrm{cmol}_{\mathrm{c}} \mathrm{dm}^{-3}$} & \multicolumn{2}{|c|}{$\%$} \\
\hline Pousio & $26 a$ & 22 a* & $44 a^{*}$ & $44 \mathrm{a}$ & 9,6 a & $9,8 \mathrm{a}$ & 53,3 a & $51,6 a$ \\
\hline Crotalária & $33 a$ & $24 a^{*}$ & 48 a* & $44 \mathrm{a}$ & 9,9 a & $9,4 a$ & $51,6 \mathrm{a}$ & $50,8 \mathrm{a}$ \\
\hline Guandu & $26 a$ & $23 a^{*}$ & 46 a* & $44 a$ & 9,5 a & 9,4 a & 53,3 a & $52,5 \mathrm{a}$ \\
\hline Mucuna & $26 a$ & $25 a^{*}$ & $51 a^{*}$ & $45 a$ & $9,4 \mathrm{a}$ & $8,6 \mathrm{a}$ & $51,6 \mathrm{a}$ & $54,9 a$ \\
\hline Sorgo & $26 a$ & 20 a* & $49 a^{*}$ & $47 a$ & $9,0 \mathrm{a}$ & $9,3 \mathrm{a}$ & 54,9 a & $52,5 \mathrm{a}$ \\
\hline C.V. (\%) & 33,6 & 17,9 & 15,8 & 16,7 & 6,0 & 6,5 & 7,0 & 6,3 \\
\hline Controle & 39,0 & 38,0 & 70,0 & 62,0 & 9,8 & 9,2 & 56,8 & 52,4 \\
\hline
\end{tabular}

* Médias nas colunas seguidas da mesma letra não diferem significativamente pelo teste de Tukey a $5 \%$ de probabilidade e as seguidas de * diferem significativamente do controle pelo teste de Dunnett a $5 \%$ de probabilidade. pH: potencial hidrogeniônico, $\mathrm{Ca}^{2+}$ : cálcio, $\mathrm{Mg}^{2+}$ : magnésio, $\mathrm{P}$ : fósforo, $\mathrm{K}^{+}$: potássio, $\mathrm{Cu}^{2+}:$ cobre, $\mathrm{Zn}^{2+}$ : zinco, $\mathrm{Fe}^{3+}$ : ferro, $\mathrm{Mn}^{2+}$ : manganês, $\mathrm{MO}$ : matéria orgânica, $\mathrm{CTC}$ : capacidade de troca catiônica, V: saturação por bases

exportação variou de 17 a 29, 18 a 30, 35 a 59 e 72 a $121 \mathrm{~kg} \mathrm{ha}^{-1}$, respectivamente para o $\mathrm{Ca}, \mathrm{Mg}, \mathrm{P}$ e $\mathrm{K}$, e de 29 a 48, 404 a 675 , 434 a 724 e 173 a $289 \mathrm{~g} \mathrm{ha}^{-1}$, respectivamente para o $\mathrm{Cu}, \mathrm{Zn}, \mathrm{Fe}$ e Mn.

As plantas de cobertura modificaram alguns dos atributos químicos do solo em relação aos teores iniciais, ou seja, elas aumentaram o teor de matéria orgânica do solo nas duas camadas consideradas e nos dois sistemas de preparo, tanto nos experimentos com o feijoeiro (Tabelas 3 e 4) como com o milho (Tabelas 5 e 6 ).

Um dos efeitos do uso de plantas de cobertura sobre a fertilidade do solo é a adição de carbono orgânico (Osterroht, 2002). Correia \& Durigan (2008) observaram, após dois anos de semeadura direta, que o sorgo, milheto, capim-pé-de-galinha (Eleusine coracana), braquiária (Brachiaria brizantha Stapf) e vegetação espontânea usados como cobertura do solo, proporcionaram aumento do teor de matéria orgânica no solo.

O aumento da matéria orgânica do solo está associado, entre outros fatores, aos níveis de resíduos vegetais depositados ao solo. Contudo, depende também da qualidade desses resíduos sobretudo no que se refere à relação $\mathrm{C} / \mathrm{N}$ e de constituintes mais recalcitrantes à decomposição microbiana, como ligninas, ceras e compostos fenólicos de alto peso molecular. É provável ser devido a esses fatores que o sorgo, apesar da sua maior produção de biomassa (Tabela 2), não tenha diferido das demais plantas de cobertura em relação ao seu efeito na matéria orgânica do solo. De Bona et al. (2006) não notaram, em Argissolo Vermelho, após oito anos de cultivo irrigado de milho ou soja, diferença entre semeadura direta e preparo convencional quanto ao estoque de carbono orgânico na camada de solo de 0,00-0,20 m mas concluíram que o aumento na adição de carbono pelas culturas irrigadas foi contrabalanceado pelo incremento causado pela irrigação na taxa de decomposição da matéria orgânica.

Nas duas camadas consideradas e nos dois sistemas de preparo as plantas de cobertura não alteraram significativamente o pH nem os teores de cálcio e magnésio trocáveis no solo em relação ao controle, seja nos experimentos com o feijoeiro (Tabelas 3 e 4) ou com o milho (Tabelas 5 e 6). A exceção foi na semeadura direta do milho, em que os teores de cálcio na camada superficial do solo sob todas as plantas de cobertura foram menores que o do controle (Tabela 6). Devido à maior produção de grãos (Tabela 2), a exportação de cálcio pelo milho foi maior que pelo feijoeiro. Nascimento et al. (2003) constataram baixa eficiência de leguminosas em reciclar o cálcio do solo. Esses autores, após três anos de cultivo de guandu, crotalária e mucuna-preta, observaram que essas leguminosas não alteraram significativamente o $\mathrm{pH}$ nem os teores de cálcio e magnésio trocáveis no solo em relação a uma área sem cultivo, com vegetação espontânea rala. Almeida et al. (2008), após 
Tabela 5. Valores médios de $\mathrm{MO}, \mathrm{pH}, \mathrm{Ca}^{2+}, \mathrm{M} \mathrm{g}^{2+}, \mathrm{P}, \mathrm{K}^{+}, \mathrm{Cu}^{2+}, \mathrm{Zn}^{2+}, \mathrm{Fe}^{3+}, \mathrm{Mn}^{2+}, \mathrm{CTC}$ e $\mathrm{V}$, de acordo com as plantas de cobertura e camadas estudadas, no experimento sob preparo convencional com a cultura do milho, em Santo Antônio de Goiás, G O, 2007*

\begin{tabular}{|c|c|c|c|c|c|c|c|c|}
\hline \multirow{2}{*}{ Tratamento } & \multicolumn{8}{|c|}{ Profundidade (m) } \\
\hline & $0-0,10$ & $0,10-0,20$ & $0-0,10$ & $0,10-0,20$ & $0-0,10$ & $0,10-0,20$ & $0-0,10$ & $0,10-0,20$ \\
\hline & \multicolumn{2}{|c|}{ MO } & \multicolumn{2}{|c|}{$\mathrm{pH}$} & \multicolumn{2}{|c|}{$\mathrm{Ca}^{2+}$} & \multicolumn{2}{|c|}{$\mathrm{Mg}^{2+}$} \\
\hline & \multicolumn{2}{|c|}{$g d^{-3}$} & \multicolumn{2}{|c|}{ áqua $(1: 2,5)$} & \multicolumn{3}{|c|}{$\mathrm{cmol}_{\mathrm{c}} \mathrm{dm}^{-3}$} & \\
\hline Pousio & $22,8 a^{*}$ & $21,0 a^{*}$ & $6,2 a$ & $6,3 \mathrm{a}$ & $3,4 \mathrm{a}$ & $3,5 \mathrm{a}$ & $1,2 \mathrm{a}$ & $1,1 \mathrm{a}$ \\
\hline Crotalária & $22,2 a^{*}$ & $20,8 a^{*}$ & $6,3 a$ & $6,3 a$ & $3,4 a$ & $3,4 \mathrm{a}$ & $1,1 \mathrm{a}$ & $1,1 \mathrm{a}$ \\
\hline Guandu & $22,5 a^{*}$ & $20,5 a^{*}$ & $6,2 a$ & $6,2 a$ & $3,4 a$ & $3,4 \mathrm{a}$ & $1,1 \mathrm{a}$ & $1,1 \mathrm{a}$ \\
\hline Mucuna & $22,5 a^{*}$ & $21,0 a^{*}$ & $6,3 a$ & $6,3 a$ & $3,5 a$ & $3,5 a$ & $1,1 \mathrm{a}$ & $1,1 \mathrm{a}$ \\
\hline Sorgo & $22,5 a^{*}$ & $21,2 a^{*}$ & $6,4 a$ & $6,4 a$ & $3,5 \mathrm{a}$ & $3,5 \mathrm{a}$ & $1,2 \mathrm{a}$ & $1,2 \mathrm{a}$ \\
\hline C.V. (\%) & 2,7 & 3,4 & 1,2 & 1,2 & 7,0 & 7,2 & 8,0 & 7,4 \\
\hline \multirow[t]{3}{*}{$\begin{array}{l}\text { c.v. }(\%) \\
\text { Controle }\end{array}$} & 20,0 & 18,0 & 6,2 & 6,3 & 3,6 & 3,8 & 1,1 & 1,2 \\
\hline & \multicolumn{2}{|c|}{$P$} & \multicolumn{2}{|c|}{$\mathrm{K}^{+}$} & \multicolumn{2}{|c|}{$\mathrm{Cu}^{2+}$} & \multicolumn{2}{|c|}{$\mathrm{Zn}^{2+}$} \\
\hline & \multicolumn{6}{|c|}{$\mathrm{mg} \mathrm{dm}^{-3}$} & & \\
\hline Pousio & $10,1 a^{*}$ & $10,3 \mathrm{a}$ & $104 a^{*}$ & 97 a* & $2,6 a$ & $2,6 a$ & $3,6 a$ & $3,4 \mathrm{a}$ \\
\hline Crotalária & $9,7 a^{*}$ & $7,9 a$ & $101 a^{*}$ & $96 a^{*}$ & $2,5 a$ & $2,6 a$ & $3,6 a$ & $3,1 \mathrm{a}$ \\
\hline Guandu & $9,8 a^{*}$ & $8,4 a$ & $103 a^{*}$ & $101 a^{*}$ & $2,6 a$ & $2,6 a$ & $3,2 a$ & $2,8 \mathrm{a}$ \\
\hline Mucuna & $14,6 a^{*}$ & $13,1 \mathrm{a}$ & $106 a^{*}$ & $99 a^{*}$ & $2,5 a$ & $2,4 a$ & $3,8 \mathrm{a}$ & $3,4 a$ \\
\hline Sorgo & $11,7 a^{*}$ & $10,5 \mathrm{a}$ & $103 a^{*}$ & $96 a^{*}$ & $2,7 a$ & $2,6 a$ & $3,2 a$ & $2,8 a$ \\
\hline C.V. (\%) & 52,2 & 44,8 & 15,0 & 16,3 & 7,8 & 7,5 & 17,9 & 13,0 \\
\hline \multirow[t]{3}{*}{ Controle } & 27,0 & 16,4 & 145,0 & 129,0 & 2,4 & 2,5 & 2,7 & 3,7 \\
\hline & \multicolumn{2}{|c|}{$\mathrm{Fe}^{3+}$} & \multicolumn{2}{|c|}{$\mathrm{Mn}^{2+}$} & \multicolumn{2}{|c|}{ CTC } & \multicolumn{2}{|c|}{ V } \\
\hline & \multicolumn{4}{|c|}{$\mathrm{mg} \mathrm{dm}^{-3}$} & \multicolumn{2}{|c|}{$\mathrm{cmol}_{\mathrm{c}} \mathrm{dm}^{-3}$} & \multicolumn{2}{|c|}{$\%$} \\
\hline Pousio & $28 a^{*}$ & $26 a^{*}$ & $66 a$ & $58 a^{*}$ & $8,4 a^{*}$ & $8,2 a^{*}$ & 57,4 a & $59,0 a$ \\
\hline Crotalária & $26 a^{*}$ & $26 a^{*}$ & $60 a$ & $52 a^{*}$ & $7,9 a^{*}$ & $7,9 a^{*}$ & $59,8 a^{*}$ & $59,0 \mathrm{a}$ \\
\hline Guandu & $26 a^{*}$ & $26 a^{*}$ & $60 \mathrm{a}$ & $52 a^{*}$ & $8,2 a^{*}$ & $8,0 a^{*}$ & $57,4 a$ & $56,6 a$ \\
\hline Mucuna & $29 a^{*}$ & $28 a^{*}$ & $60 a$ & $58 a^{*}$ & $8,2 a^{*}$ & $8,0 a^{*}$ & $59,8 a^{*}$ & $59,8 \mathrm{a}$ \\
\hline Sorgo & 33 a* & 29 a* & $65 a$ & $59 a^{*}$ & $8,0 a^{*}$ & $7,9 a^{*}$ & $62,3 a^{*}$ & $61,5 a^{*}$ \\
\hline C.V. (\%) & 10,8 & 8,7 & 6,8 & 9,2 & 4,7 & 4,8 & 4,3 & 4,3 \\
\hline Controle & 43,0 & 49,0 & 79,0 & 86,0 & 9,8 & 9,8 & 52,9 & 54,3 \\
\hline
\end{tabular}

* Médias nas colunas seguidas da mes ma letra não diferem significativamente pelo teste de Tukey a $5 \%$ de probabilidade e as seguidas de * diferem significativamente do controle pelo teste de Dunnett a $5 \%$ de probabilidade. $\mathrm{pH}$ : potencial hidrogeniônico, $\mathrm{Ca}^{2+}$ : cálcio, $\mathrm{Mg}^{2+}$ : magnésio, $\mathrm{P}$ : fósforo, $\mathrm{K}^{+}$: potássio, $\mathrm{Cu}^{2+}:$ cobre, $\mathrm{Zn}^{2+}:$ zinco, $\mathrm{Fe}^{3+}$ : ferro, $\mathrm{Mn}^{2+}:$ manganês, $\mathrm{M} 0$ : matéria orgânica, $\mathrm{CTC}$ : capacidade de troca catiônica, V: saturação por bases

três anos de semeadura direta ou com preparo convencional do solo, também não verificaram efeito significativo dessas leguminosas e do milheto e pousio sobre o $\mathrm{pH}$ e os teores de cálcio e magnésio trocáveis no solo.

O teor de fósforo disponível na camada superficial do solo nos experimentos com preparo convencional diminuiu em relação à análise inicial, para todas as plantas de cobertura (Tabelas 3 e 5). Como os experimentos não foram adubados, infere-se que a reciclagem pelas plantas de cobertura não foi suficiente para compensar a exportação do fósforo pelos grãos de feijão e de milho e sua adsorção ao solo. Na semeadura direta esta redução só ocorreu para a mucuna nos experimentos com feijoeiro e com milho e para a crotalária e o sorgo no experimento com milho (Tabelas 4 e 6). Possivelmente, a pouca mobilidade do fósforo no solo, a redução na sua adsorção em razão do seu menor contato com os constituintes inorgânicos do solo, devido à não-incorporação dos resíduos e o aumento da atividade microbiana e ciclagem do fósforo orgânico (De Maria et al., 1999; Correia \& Durigan, 2008), devem ter contribuído para a menor redução do teor de fósforo na semeadura direta. Segundo Pavinato \& Rosolem (2008), é normal se observar o aumento na disponibilidade de fósforo no solo com resíduos vegetais, tanto pelo fósforo presente no resíduo como por competição de compostos orgânicos dos resíduos pelos sítios de troca no solo.
Na camada de 0,10-0,20 m o teor de fósforo disponível no solo sob as plantas de cobertura não diferiu do controle em todos os experimentos, com exceção do preparo convencional do feijoeiro, em que este teor foi menor sob pousio, guandu e sorgo.

Após quatro anos sob preparo convencional o teor de fósforo disponível no solo se situou entre baixo e médio. $\mathrm{Na}$ semeadura direta, por sua vez, ele se manteve entre médio e alto, segundo Souza \& Lobato (2004).

Com exceção dos experimentos com o feijoeiro sob preparo convencional, nas duas camadas consideradas (Tabela 3) e sob semeadura direta, na camada de 0,10-0,20 m (Tabela 4), em que as plantas de cobertura não alteraram significativamente $o$ teor de potássio disponível no solo em relação ao controle, nos demais o teor diminuiu nas duas camadas (Tabelas 5 e 6). Pode-se inferir que a reciclagem desse elemento pelas plantas de cobertura não está sendo suficiente para suprir as quantidades retiradas com a colheita de grãos, especialmente pelo milho. Ainda assim, os teores de potássio variaram de adequado a alto, segundo Souza \& Lobato (2004). Nascimento et al. (2003) não encontraram diferença significativa na reciclagem do potássio entre guandu, crotalária e mucuna-preta.

Nas duas camadas consideradas e nos dois sistemas de preparo as plantas de cobertura não alteraram significativamente o teor de cobre disponível no solo em relação ao controle, 
Tabela 6. Valores médios de $\mathrm{MO}, \mathrm{pH}, \mathrm{Ca}^{2+}, \mathrm{Mg}^{2+}, \mathrm{P}, \mathrm{K}^{+}, \mathrm{Cu}^{2+}, \mathrm{Zn}^{2+}, \mathrm{Fe}^{3+}, \mathrm{Mn}^{2+}, \mathrm{MO}, \mathrm{CTC}$ e $\mathrm{V}$, de acordo com as plantas de cobertura e camadas estudadas, no experimento sob semeadura direta com a cultura do milho, em Santo Antônio de Goiás, GO, 2007*

\begin{tabular}{|c|c|c|c|c|c|c|c|c|}
\hline \multirow{2}{*}{ Tratamento } & \multicolumn{8}{|c|}{ Profundidade (m) } \\
\hline & $0-0,10$ & $0,10-0,20$ & $0-0,10$ & $0,10-0,20$ & $0-0,10$ & $0,10-0,20$ & $0-0,10$ & $0,10-0,20$ \\
\hline & \multicolumn{2}{|c|}{ MO } & \multicolumn{2}{|c|}{$\mathrm{pH}$} & \multicolumn{2}{|c|}{$\mathrm{Ca}^{2+}$} & \multicolumn{2}{|c|}{$\mathrm{Mg}^{2+}$} \\
\hline & \multicolumn{2}{|c|}{$g \mathrm{dm}^{-3}$} & \multicolumn{2}{|c|}{ água $(1: 2,5)$} & \multicolumn{4}{|c|}{$\mathrm{cmol}_{\mathrm{c}} \mathrm{dm}^{-3}$} \\
\hline Pousio & $22,0 a^{*}$ & $20,5 a^{*}$ & $6,4 a$ & $6,4 a$ & $3,6 a^{*}$ & $3,4 a$ & $1,3 \mathrm{a}$ & $1,2 \mathrm{a}$ \\
\hline Crotalária & $22,5 a^{*}$ & $20,8 a^{*}$ & $6,3 \mathrm{a}$ & $6,2 \mathrm{a}$ & $3,3 a^{*}$ & $3,3 a$ & $1,2 \mathrm{a}$ & $1,1 \mathrm{a}$ \\
\hline Guandu & $22,8 a^{*}$ & $21,0 a^{*}$ & $6,4 \mathrm{a}$ & $6,3 a$ & $3,6 a^{*}$ & $3,6 a$ & $1,2 \mathrm{a}$ & $1,2 \mathrm{a}$ \\
\hline Mucuna & $22,0 a^{*}$ & $20,5 a^{*}$ & $6,3 a$ & $6,2 \mathrm{a}$ & $3,4 a^{*}$ & $3,3 a$ & $1,2 \mathrm{a}$ & $1,2 a$ \\
\hline Sorgo & $22,5 a^{*}$ & $20,5 a^{*}$ & $6,3 \mathrm{a}$ & $6,3 a$ & $3,5 a^{*}$ & $3,2 a$ & $1,3 a$ & $1,1 \mathrm{a}$ \\
\hline C.V. $(\%)$ & 1,9 & 2,8 & 2,1 & 2,0 & 7,1 & 10,3 & 11,3 & 12,2 \\
\hline \multirow[t]{3}{*}{ Controle } & 21,0 & 18,0 & 6,4 & 6,2 & 4,1 & 3,6 & 1,4 & 1,1 \\
\hline & \multicolumn{2}{|c|}{$P$} & \multicolumn{2}{|c|}{$\mathrm{K}^{+}$} & \multicolumn{2}{|c|}{$\mathrm{Cu}^{2+}$} & \multicolumn{2}{|c|}{$\mathrm{Zn}^{2+}$} \\
\hline & \multicolumn{8}{|c|}{$\mathrm{mg} \mathrm{dm}^{-3}$} \\
\hline Pousio & $28,7 \mathrm{a}$ & $24,4 a$ & $97 a^{*}$ & $92 a^{*}$ & $2,2 \mathrm{a}$ & $2,0 a$ & $3,2 \mathrm{a}$ & $3,1 \mathrm{a}$ \\
\hline Crotalária & $20,7 a^{*}$ & $20,6 \mathrm{a}$ & $93 a^{*}$ & $88 a^{*}$ & $2,0 \mathrm{a}$ & $2,0 \mathrm{a}$ & $3,4 a$ & $3,1 \mathrm{a}$ \\
\hline Guandu & 26,6 a & $20,2 \mathrm{a}$ & 98 a* & 90 a* & $1,9 a$ & $1,8 \mathrm{a}$ & $3,6 a$ & $2,7 a$ \\
\hline Mucuna & $20,0 a^{*}$ & $16,6 \mathrm{a}$ & $104 a^{*}$ & $98 a^{*}$ & $2,0 \mathrm{a}$ & $1,9 a$ & $3,7 \mathrm{a}$ & $3,1 \mathrm{a}$ \\
\hline Sorgo & $16,7 a^{*}$ & $12,7 \mathrm{a}$ & $92 \mathrm{a}^{*}$ & $79 a^{*}$ & $2,2 \mathrm{a}$ & $2,1 a$ & $3,7 \mathrm{a}$ & $3,3 a$ \\
\hline C.V. $(\%)$ & 36,9 & 42,3 & 15,6 & 19,4 & 17,2 & 7,7 & 23,0 & 38,1 \\
\hline \multirow[t]{3}{*}{ Controle } & 37,2 & 22,1 & 140,0 & 126,0 & 1,9 & 2,0 & 3,0 & 2,6 \\
\hline & \multicolumn{2}{|c|}{$\mathrm{Fe}^{3+}$} & \multicolumn{2}{|c|}{$\mathrm{Mn}^{2+}$} & \multicolumn{2}{|c|}{ CTC } & \multicolumn{2}{|c|}{ V } \\
\hline & \multicolumn{4}{|c|}{$\mathrm{mg} \mathrm{dm}^{-3}$} & \multicolumn{2}{|c|}{$\mathrm{cmol}_{\mathrm{c}} \mathrm{dm}^{-3}$} & \multicolumn{2}{|c|}{$\%$} \\
\hline Pousio & 23 a* & $22 a^{*}$ & $52 a^{*}$ & $46 a^{*}$ & $8,2 a^{*}$ & $8,0 a^{*}$ & $62,3 \mathrm{a}$ & $60,7 a$ \\
\hline Crotalária & 22 a* & $21 a^{*}$ & $56 a^{*}$ & $52 a^{*}$ & $8,1 a^{*}$ & $8,1 a^{*}$ & $58,2 \mathrm{a}$ & $57,4 \mathrm{a}$ \\
\hline Guandu & 22 a* & $22 a^{*}$ & $52 a^{*}$ & $49 a^{*}$ & $8,7 a^{*}$ & $8,5 a^{*}$ & $60,7 a$ & $58,2 \mathrm{a}$ \\
\hline Mucuna & 26 a* & $26 a^{*}$ & $56 a^{*}$ & $51 a^{*}$ & $8,4 a^{*}$ & 8,5 a* & $58,2 \mathrm{a}$ & 55,7 a \\
\hline Sorgo & $23 a^{*}$ & $20 a^{*}$ & $57 a^{*}$ & $53 a^{*}$ & $8,5 a^{*}$ & $7,7 a^{*}$ & $59,0 \mathrm{a}$ & $59,8 \mathrm{a}$ \\
\hline C.V. (\%) & 17,4 & 18,2 & 7,9 & 10,6 & 4,4 & 6,9 & 7,4 & 7,0 \\
\hline Controle & 43,0 & 45,0 & 78,0 & 72,0 & 9,9 & 9,7 & 58,8 & 52,3 \\
\hline
\end{tabular}

* Médias nas colunas seguidas da mesma letra não diferem significativamente pelo teste de Tukey a $5 \%$ de probabilidade e as seguidas de * diferem signific ativamente do controle pelo teste de Dunnett a $5 \%$ de probabilidade. pH: potencial hidrogeniônico, $\mathrm{Ca}^{2+}$ : cálcio, $\mathrm{Mg}^{2+}$ : magnésio, $\mathrm{P}$ : fósforo, $\mathrm{K}^{+}$: potássio, $\mathrm{Cu}^{2+}$ : cobre, $\mathrm{Zn}^{2+}$ : zinco, $\mathrm{Fe}^{3+}$ : ferro, $\mathrm{Mn}^{2+}$ : manganês, $\mathrm{MO}$ : matéria orgânica, $\mathrm{CTC}$ : capacidade de troca catiônica, V: saturação por bases

tanto nos experimentos com o feijoeiro (Tabelas 3 e 4) como com o milho (Tabelas 5 e 6). A principal fonte desse micronutriente é a matéria orgânica e, como o seu teor aumentou em relação ao controle, possivelmente a liberação do cobre pela mineralização da M.O. contrabalanceou sua exportação pelas culturas do feijoeiro e do milho. Teixeira et al. (2003) encontraram correlação linear positiva entre os teores de carbono orgânico e de cobre, sob diversos preparos do solo, o que não foi verificado neste trabalho. Castro et al. (1992) também não encontraram correlação entre os teores de matéria orgânica e de cobre.

Nos experimentos com o feijoeiro sob preparo convencional os teores de zinco disponível no solo sob guandu, mucuna e sorgo, nas duas camadas e sob pousio, na camada de $0,10-0,20$ $\mathrm{m}$, foram menores em relação aos do controle (Tabela 3). Por sua vez, na semeadura direta as plantas de cobertura não alteraram significativamente o teor de zinco nas duas camadas consideradas (Tabela 4). Com o milho isto se verificou para os dois sistemas de preparo do solo (Tabelas 5 e 6). Andreola et al. (2000) também verificaram que a cobertura de inverno não afetou o teor de zinco disponível. A matéria orgânica é uma das principais fontes desse micronutriente (Teixeira et al., 2003; Zanão Júnior et al., 2007) e houve tendência do seu teor ser maior nos experimentos com milho. A correlação entre os teores de matéria orgânica e de zinco foi positiva e significativa $(r=$
0,59, $\mathrm{p}<0,01)$, concordando com os resultados de Castro et al. (1992). Tal como no caso do cobre, possivelmente a liberação do zinco pela mineralização da M.O contrabalanceou sua exportação pelas culturas do feijoeiro e do milho. A redução no teor de zinco sob preparo convencional, por sua vez, pode ser devida à sua diluição no perfil pelo revolvimento do solo.

Nas duas camadas consideradas e nos dois sistemas de preparo para todas as plantas de cobertura, os teores de ferro disponível no solo foram menores em relação aos do controle, tanto nos experimentos com o feijoeiro (Tabelas 3 e 4), como com o milho (Tabelas 5 e 6), com exceção da semeadura direta do feijoeiro, em que os teores de ferro na camada superficial do solo sob todas as plantas de cobertura não diferiram do controle. Embora o ferro seja reciclado em maiores quantidades que outros micronutrientes, seu aumento nas camadas superficiais pode não ocorrer devido à rápida oxidação desse elemento ao ser liberado da matéria orgânica (Shuman \& Hargrove, 1985).

Teixeira et al. (2003) observaram menores teores de ferro e maiores de carbono orgânico sob semeadura direta e preparo com grade pesada em comparação a outros preparos do solo e atribuíram, ao poder complexante da matéria orgânica, o menor teor de ferro observado. Zanão Júnior et al. (2007) também observaram, em Latossolo Vermelho sob semeadura direta, menor teor de ferro na camada superficial em razão do maior teor de matéria orgânica. Contudo, Alleoni et al. (2005) não 
encontraram correlação entre esses teores, o que também foi verificado neste trabalho. Como a redução no teor de ferro foi bem maior que a quantidade exportada pelos grãos de feijão e milho, infere-se que a complexação do ferro pela matéria orgânica deve ter exercido papel relevante nesse resultado. A manutenção pelas plantas de cobertura do pH elevado ao longo do tempo também pode ter contribuído para a indisponibilidade desse elemento. Alleoni et al. (2005) verificaram correlação negativa entre o $\mathrm{pH}$ e o teor de ferro.

Nos experimentos com o feijoeiro sob preparo convencional para todas as plantas de cobertura, os teores de manganês disponível no solo foram menores em relação aos do controle, nas duas camadas consideradas (Tabela 3). Sob semeadura direta o mesmo se verificou na camada superficial do solo enquanto na camada de 0,10-0,20 $\mathrm{m}$ as plantas de cobertura não alteraram este teor em relação ao controle (Tabela 4). Com o milho sob preparo convencional, as plantas de cobertura não alteraram o teor de manganês na camada superficial do solo em relação ao do controle. Na camada de 0,10-0,20 m e na semeadura direta nas duas camadas os teores de manganês disponível no solo foram menores em relação aos do controle (Tabelas 5 e 6). Assim como para os demais micronutrientes avaliados, uma das suas principais fontes é a matéria orgânica, cujo teor aumentou em relação ao controle. Castro et al. (1992), em solos sob semeadura direta ou preparo convencional, e Teixeira et al. (2003), sob diversos preparos do solo, constataram correlação linear positiva entre os teores de carbono orgânico e de manganês. Neste trabalho também foi verificada correlação linear positiva entre esses teores $(r=0,69$, $\mathrm{p}<0,01)$. Desta maneira, era de se esperar que a mineralização da matéria orgânica fosse suficiente para compensar a exportação do manganês pelas culturas do feijoeiro e do milho. É provável que a manutenção pelas plantas de cobertura do pH elevado ao longo do tempo tenha contribuído para a indisponibilidade desse elemento. Alleoni et al. (2005) verificaram correlação negativa entre o pH e o teor de manganês. Com o aumento do $\mathrm{pH}$ este elemento forma compostos de menor solubilidade, como precipitados ou óxidos.

Verificou-se, após quatro anos que, em geral, o cultivo de plantas de coberturas não foi suficiente para manter os teores de ferro e de manganês nos mesmos níveis iniciais. Ainda assim, os teores de todos os micronutrientes avaliados se mantiveram classificados como altos, segundo Souza \& Lobato (2004).

Nas duas camadas consideradas e nos dois sistemas de preparo do solo, as plantas de cobertura não alteraram significativamente a capacidade de troca de cátions a pH 7 (CTC) em relação ao controle, nos experimentos com o feijoeiro (Tabelas 3 e 4). Nascimento et al. (2003) observaram, após três anos de cultivo de guandu, crotalária e mucuna-preta, que essas leguminosas não alteraram significativamente a CTC do solo em relação a uma área sem cultivo, com vegetação espontânea rala.

Com o milho nas duas camadas e nos dois sistemas de preparo, os valores de CTC sob as plantas de cobertura foram menores que no controle (Tabelas 5 e 6), o que se deve, possivelmente, à maior exportação de cálcio e potássio pelos grãos de milho.

Nos experimentos com o feijoeiro nos dois sistemas de preparo do solo as plantas de cobertura não alteraram significativamente a saturação por bases (V) em relação ao controle, nas duas camadas consideradas (Tabelas 3 e 4). Nascimento et al. (2003) constataram que o guandu, crotalária e mucuna-preta, embora com valores absolutos maiores, não diferiram significativamente de uma área sem cultivo no seu efeito sobre V.

Com o milho sob preparo convencional, crotalária e mucuna, na camada superficial, e sorgo, nas duas camadas, aumentaram significativamente $\mathrm{V}$ em relação ao controle (Tabela 5). Sob semeadura direta as plantas de cobertura não diferiram do controle (Tabela 6). Os maiores valores de $\mathrm{V}$ foram devidos aos menores valores de $\mathrm{H}^{+}+\mathrm{Al}^{3+}$ (dados não apresentados), possivelmente em consequência de valores mais elevados de $\mathrm{pH}$, embora sem diferença estatística, sob aquelas plantas de cobertura. Teixeira et al. (2003) verificaram que a adição de restos orgânicos ao solo promoveu neutralização da acidez potencial, aumentando as cargas negativas do solo disponíveis para a adsorção de cátions básicos. A redução da acidez potencial pode ser atribuída ao efeito do $\mathrm{pH}$ nas cargas variáveis do solo.

\section{CONCLUSÕES}

1. Após quatro anos de cultivo as plantas de cobertura não diferiram entre si quanto aos seus efeitos nos atributos químicos do solo, seja sob semeadura direta ou sob preparo convencional do solo.

2. As plantas de cobertura elevaram o teor de matéria orgânica em relação à condição inicial, independentemente do preparo do solo e da cultura principal.

3. Em geral, a reciclagem dos nutrientes pelas plantas de cobertura, seja sob semeadura direta ou sob preparo convencional do solo, não foi suficiente para a manutenção dos teores de fósforo, potássio, ferro e manganês no solo.

\section{LITERATURA CITADA}

Alcântara, F. A.; Furtini Neto, A. E.; Paula, M. B.; Mesquita, H. A.; Muniz, J. A. Adubação verde na recuperação da fertilidade de um Latossolo Vermelho escuro degradado. Pesquisa Agropecuária Brasileira, v.35, p.277-288, 2000.

Alleoni, L. R. F.; Cambri, M. A.; Caires, E. F. Atributos químicos de um latossolo de Cerrado sob plantio direto, de acordo com doses e formas de aplicação de calcário. Revista Brasileira de Ciência do Solo, v.29, p.923-934, 2005.

Almeida, V. P. de; Alves, M. C.; Silva, E. C. da; Oliveira, S. A. de. Rotação de culturas e propriedades físicas e químicas em Latossolo Vermelho de cerrado sob preparo convencional e semeadura direta em adoção. Revista Brasileira de Ciência do Solo, v.32, p.1227-1237, 2008.

Alves, M. C.; Suzuki, L. E. A. S. Influência de diferentes sistemas de manejo do solo na recuperação de suas propriedades físicas. Acta Scientiarum Agronomy, v.26, p.27-34, 2004.

Andreola, F.; Costa, L. M.; Mendonça, E. S.; Olszevski, N. Propriedades químicas de uma Terra Roxa Estruturada influenciadas pela cobertura vegetal de inverno e pela adubação orgânica e mineral. Revista Brasileira de Ciência do Solo, v.24, p.609-620, 2000. 
Anghinoni, I.; Nicolodi, M. Estratégias de calagem no sistema plantio direto. In: Reunião Brasileira de Fertilidade do Solo e Nutrição de Plantas, 26., 2004, Lages. Anais... Lages: Sociedade Brasileira de Ciência do Solo, 2004. CD-Rom.

Castro, O. M. de; Camargo, O. A. de; Cantarella, H.; Vieira, S. R.; Dechen, S. C. F. Teores de zinco, cobre, manganês e ferro em dois latossolos sob plantios direto e convencional. Bragantia, v.51, p.77-84, 1992.

Correia, N. M.; Durigan, J. C. Culturas de cobertura e sua influência na fertilidade do solo sob sistema de plantio direto (SPD). Bioscience Journal, v.24, p.20-31, 2008.

De Bona, F. D.; Bayer, C.; Bergamaschi, H.; Dieckow, J. Carbono orgânico no solo em sistemas irrigados por aspersão sob plantio direto e preparo convencional. Revista Brasileira de Ciência do Solo, v.30, p.911-919, 2006.

De Maria, I. C.; Castro, O. M. Fósforo, potássio e matéria orgânica em um Latossolo Roxo, sob sistemas de manejo com milho e soja. Revista Brasileira de Ciência do Solo, v.17, p.471-477, 1993.

De Maria, I. C.; Nnabude, P. C.; Castro, O. M. de. Long-term tillage and crop rotation effects on soil chemical properties of a Rhodic Ferralsol in southern Brazil. Soil \& Tillage Research, v.51, p.71-79, 1999.

Denardin, J. E. ; Kochhann, R. A. Requisitos para a implantaçãoe a manutenção do sistema plantio direto. In: CNPT-EMBRAPA, FUNDACEP-FECOTRIGO, Fundação ABC. Plantio Direto no Brasil. Passo Fundo: Aldeia Norte, 1993. p.19-27.

EMBRAPA - Empresa Brasileira de Pesquisa Agropecuária. Centro Nacional de Pesquisa de Solos. Manual de métodos de análise de solos. 2.ed. Rio de Janeiro: Embrapa CNPS, 1997. 212p. Documentos, 1.

Fageria, N. K. Resposta de arroz de terras altas, feijão, milho e soja à saturação por base em solo de cerrado. Revista Brasileira de Engenharia Agrícola e Ambiental, v.5, p.416424, 2001.

Menezes, L. A. S.; Leandro, W. M. Avaliação de espécies de coberturas do solo com potencial de uso em sistema de plantio direto. Pesquisa Agropecuária Tropical, v.34, p.173180, 2004.

Menezes, L. A. S.; Leandro, W. M.; Oliveira Júnior, J. P. de; Ferreira, A. C. de B.; Santana, J. das G.; Barros, R. G. Produção de fitomassa de diferentes espécies, isoladas e consorciadas, com potencial de utilização para cobertura do solo. Bioscience Journal, v.25, p.7-12, 2009.

Moreti, D.; Alves, M. C.; Valério Filho, W. V.; Carvalho, M. de P. Atributos químicos de um Latossolo Vermelho sob diferentes sistemas de preparo, adubações e plantas de cobertura. Revista Brasileira de Ciência do Solo, v.3, p.167-175, 2007.
Nascimento, J. T.; Silva, I. F. da; Santiago, R. D.; Silva Neto, L. de F. da. Efeito de leguminosas nas características químicas e matéria orgânica de um solo degradado. Revista Brasileira de Engenharia Agrícola e Ambiental, v.7, p.457462, 2003.

Osterroht, M. von. O que é uma adubação verde: Princípios e ações. Agroecologia Hoje, v.14, p.9-11, 2002.

Pavinato, P. S.; Rosolem, C. A. Disponibilidade de nutrientes no solo - decomposição e liberação de compostos orgânicos de resíduos vegetais. Revista Brasileira de Ciência do Solo, v.32, p.911-920, 2008.

Perin, A.; Santos, R. H. S.; Urquiaga, S.; Guerra, J. G. M.; Cecon, P. R. Produção de fitomassa, acúmulo de nutrientes e fixação biológica de nitrogênio por adubos verdes em cultivo isolado e consorciado. Pesquisa Agropecuária Brasileira, v.39, p.35-40, 2004.

SAS Institute Inc. SAS/STAT procedure guide for personal computers: version 5. Cary: SAS Institute, 1999. 1042p.

Shuman, L. M.; Hargrove, L. Effect of tillage on the distribution of manganese, copper, iron and zinc in soil fractions. Soil Science Society of America Journal, v.49, p.1117-1121, 1985.

Silva, S. C. da; Heinemann, A. B.; Paz, R. L. F.; Amorim, A. de O. Informações meteorológicas para pesquisa e planejamento agrícola, referentes ao ano de 2009, do município de Santo Antônio de Goiás, GO. Santo Antônio de Goiás: Embrapa Arroz e Feijão, 2010. 32p. Documentos, 256.

Souza, D. M. G.; Lobato, E. Cerrado: Correção do solo e adubação. 2.ed. Brasília: Embrapa Informação Tecnológica, 2004. 416p.

Teixeira, I. R.; Souza, C. M. de; Borém, A.; Silva, G. F. da. Variação dos valores de $\mathrm{pH}$ e dos teores de carbono orgânico, cobre, manganês, zinco e ferro em profundidade em Argissolo Vermelho-Amarelo, sob diferentes sistemas de preparo do solo. Bragantia, v.62, p.119-126, 2003.

Walkley, A.; Black, I. A. An examination of the Degtjareff method for determining soil organic matter, and a proposed modification of the chromic acid titration method. Soil Science, v.37, p.29-38, 1934.

Wutke, E. B.; Arruda, F. B.; Fancelli, A. L.; Pereira, J. C. V. N. A.; Sakai, E.; Fusiwara, M.; Ambrosano, G. M. B. Propriedades do solo e sistema radicular do feijoeiro irrigado em rotação de culturas. Revista Brasileira de Ciência do Solo, v.24, p.621633, 2000.

Zanão Júnior, L. A.; Lana, R. M. Q.; Guimarães, E. C. Variabilidade espacial do $\mathrm{pH}$, teores de matéria orgânica e micronutrientes em profundidades de amostragem num Latossolo Vermelho sob semeadura direta. Ciência Rural, v.37, p.1000-1007, 2007. 